\title{
Habituation of the GSR and of breathing disturbances in the cat
}

DELOS D. WICKEHS, ANTHOHY F. HIELD AND CAROL D. WICKENS

THE OHIO STATE UNIVERSITY ${ }^{1}$

The habituation of the GSR and breathing disturbances elicited by a compound stimulus was observed in six cats over 12 daily sessions. Some recovery of response occurred between sessions. Presentation of two spaced shocks failed to produce disinhibition. The two responses were relatively independent.

This study describes the habituation of the GSR and breathing disturbances in cats, elicited by a compound stimulus of light and tone, which was eventually to become a CS with a shock as the UCS. Since the eventual CR would consist of GSR and breathing disturbances, it was necessary to eliminate the initial orienting reflexes (Sokolov, 1963) to the CS.

\section{Subjects}

The Ss were four male and two spayed cats 18 to 24 months of age.

\section{Apparafus}

Breathing and GSR were recorded on Sanborn 320 Recorders. Zinc electrodes $9 / 16$ in. diameter in plastic cups filled with zinc sulphate bactoagar jelly measured the GSR through the cat's right paw. Breathing was reflected by a strain gage (mounted on a bridge attached to a shoestring which encircled the cat's chest), and a Sanborn 1100 Carrier Preamplifier. An oscillator generated the tone, and the light was produced by a bank of five bulbs (total voltage of 40) mounted behind a $5 \times 5$ in. frosted glass panel 6 in. in front of the cat. Tektronix Pulse and Waveform Generators controlled timing. An Applegate 250 Stimulator through electrodes on the cat's left paw produced the shock. The animals were located in a Model 402 IAC room, equipment being outside this room.

\section{Procedure}

The cat was adapted to the test room, the sling in which it was to hang, and the wearing of the recording and shock electrodes (Wickens, Meyer, \& Sullivan, 1961). It was then given $60 \mathrm{msec}$. shocks to find the level which would produce a clear GSR without being disturbing. Levels ranged from 1.7 to $2.0 \mathrm{ma}$. Adaptation to light-tone compound was then begun. The tone was $1000 \mathrm{cps}$ at $75 \mathrm{~dB}$, or $20 \mathrm{~dB}$ above room noise; brightness of light was adjusted to appear to have the same salience as tone. The two stimuli began and ended together and their duration was $2000 \mathrm{msec}$.

Since initially the cats became restive if a session lasted over $10 \mathrm{~min}$., number of daily stimulations was increased according to the following schedule: $4,4,6$, 7 , then 10 for the remaining eight days. On the last two days, an appropriate shock was given on the first and fifth trials to determine whether the noxious stim- ulus would disinhibit the adapted response to the compound.

Results

Figure 1 shows the course of habituation of GSRs and breathing disturbances. The latter were read by visual inspection and were classified as responses if there was a disturbance in base, line, rate, or amplitude. Habituation occurs for both responses, with the GSR showing the greater amount. Introduction of the shock did not increase responsiveness. Figure 2 indicates the mean GSR magnitude for all trials on each day, with the vertical bars plotting the mean response during the first and second halves of the day. The first half is consistently higher than the second, and the first half of each succeeding day is greater than the last half of the preceding day. Breathing responses do not show the same trend, being about equal for the two halves of the day.

\section{Discussion}

The data of the experiment may be considered with respect to habituation theory (Thorpe, 1966) and the orienting reflex. According to Sokolov (1963), the presence of the OR is reflected in breathing changes and also in the GSR, and it adapts with repeated stimulation. Our results support this common finding.

Our experiment differs from the usual habituation experiment in that adaptation sessions continued over successive days. As Fig. 1 shows, some recovery

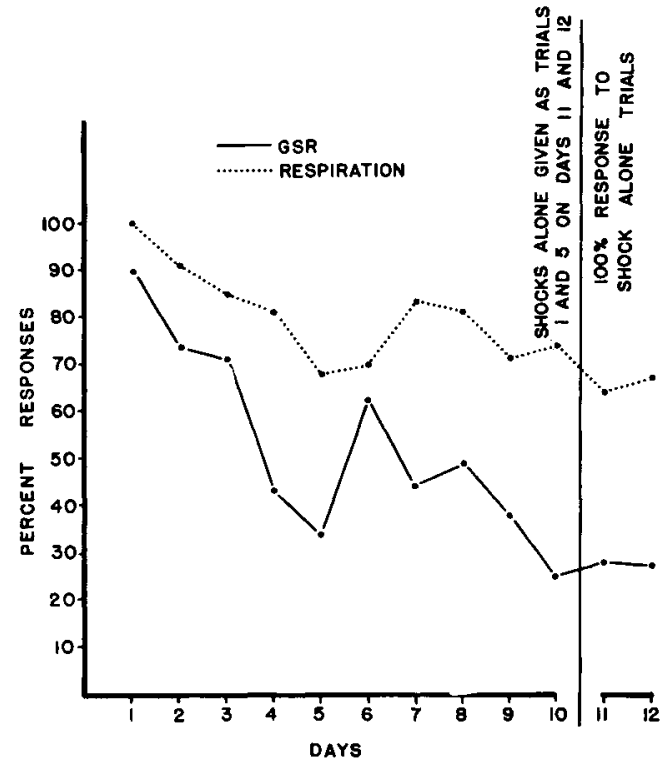

Fig. 1. Habituation of the GSR and breathing responses. 

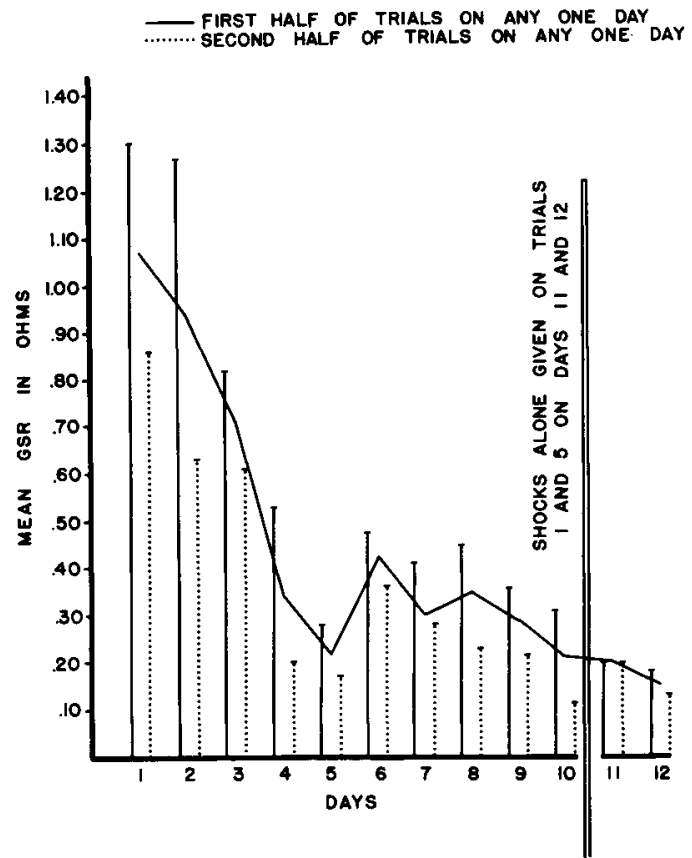

Fig. 2. Habituation across and within days for the GSR.

occurs between successive sessions, a finding consistent with the work of Gastaut \& Bert (1961). Figure 2 illustrates the phenomenon of within-session adaptation, GSR responses during the second half of the period being lower than those of the first half. Perhaps the response decrement occurring within a session is not exclusively a phenomenon of habituation, but includes also a certain amount of response suppression associated with the immediate situation. This could arise from an artifact of "tissue change" of the skin from the GSR current passing through the paw (Edelberg, Greiner, \& Burch, 1960).

As a test of the possibility of tissue change from prolonged GSR current during the experimental session, a small experiment was performed on two new cats who had two different experimental procedures alternated for eight days. Both procedures started the daily session with a throw-away initial shock with the Fels circuit open (GSR off) since responses to initial shock are erratic. The circuit was then closed (GSR on) for 45 sec., and a second shock given and recorded. For one procedure the circuit remained closed for nine stimulations $(7.5 \mathrm{~min}$.) and for a final recorded shock response. For the other procedure, the circuit was opened after the first recorded shock and nine compound stimulations $(7.5 \mathrm{~min}$.) given with no GSR current passing through the paw. The circuit was then closed and the final shock recorded. Each cat received four days of one procedure and four days of the other alternately, and it became possible to measure the influence of continued current flow through the paw across the experimental period. For each cat for each day, a ratio was obtained by subtracting the ohms response of the second trial from that of the first and dividing by the value of the first. One cat showed a slight increase in ratio, the other an equivalent decrease. This was true of ohms response as well. There seemed to be no evidence that the passage of the current caused a diminution in the magnitude of the GSR under these conditions, and it may indeed be that a real phenomenon of temporary adaptation has been shown.

Lynn (1966, p. 28) reports that disinhibition occurs if a strong stimulus is introduced following habituation. Certainly two shocks could have served as disinhibitors, for in all cases they produced sizeable GSRs, the mean GSR to shock on the two days being larger than any OR given during the 12 days. Nevertheless, they failed to do so. However, the shock preceded the next complex by 30 to $60 \mathrm{sec}$., and it is possible that the arousal effect had dissipated before the next stimulus was given (Sharpless \& Jasper, 1956; Thompson \& Spencer, 1966).

To what extent do breathing and the GSR reflect the same central process, namely the OR? Although both responses decrease across trials (Fig. 1), their courses are not parallel. Fisher's Exact Probability Test $\left(\mathrm{X}^{2}\right)$ was used on the data of each $S$ to determine if there was a significant tendency for the GSR and breathing disturbances to occur together on given trials. In no instance did the $\mathrm{p}$ value reach significance, the closest being .10 for one cat. It would seem that the two responses are not closely linked to the same intervening state, as the OR concept in the literature suggests.

\section{References}

Edelberg, A., Greiner, T., \& Burch, N. R. Some membrane properties of the effector in the galvanic skin responses. J. appl. Physiol., 1960, 15, 691-696.

Gastaut, H., \& Bert, J. Electrode encephalographic detection of sleep induced by repetitive sensory stimuli. In G. E. Wolstenholme and M. O'Connor (Eds.), The nature of sleep. London: Churchill Press, 1961.

Lynn, R. Attention, arousal and the orientation reaction. New York: Pergamon Press, 1963.

Sokolov, Y. N. Perception and the conditioned reflex. New York: Pergamon Press, 1963.

Thompson, R. F., \& Spencer, W. A. Habituation: A model phenomenon for the study of neuronal substrates of behavior. Psychol. Rev., 1966, 73, 16-43.

Thorpe, W. H. Learning and instinct in animals. Cambridge: Harvard University Press, 1963.

Wickens, D. D., Meyer, P. M., \& Sullivan, S. N. Classical GSR conditioning, conditioned discrimination, and interstimulus interval in cats. $J$. comp. physiol. Psychol., 1961, 54, 572-576.

Note

1. This research was supported by USPH grant number MH-08423. 